\title{
RANCANG BANGUN PENGELOMPOKAN BAKAT KEMAMPUAN BEKERJA BERBASIS DEKSTOP PADA TELKOMSIGMA JAKARTA
}

\author{
Jully Triansyah, M.Kom', Dicky Rodika Aji ${ }^{2}$ \\ 1,2Fakultas Teknik Program Studi Informatika, Universitas Muhammadiyah Tangerang \\ Jalan Perintis Kemerdekaan I Babakan No.33, Cikokol, Kec. Tangerang, Kota Tangerang, Banten \\ 15118 \\ Co Responden Email : trian.juli@ft-umt.ac.id
}

\author{
Article history \\ Received Nov 26, 2020 \\ Revised Des 11, 2020 \\ Accepted Feb 05, 2021 \\ Available online Feb 27, \\ 2021 \\ Keywords \\ Ability, C\#, DevExpress, \\ Extreme Programming, \\ $I D E$
}

Abstract

With the existence of highly advanced information technology as it is today, it is certainly very helpful for human work in creating, changing and seeking information. The process of searching for information at Telkomsigma Jakarta still uses a system that is not well computed. In designing this talent grouping application, the author uses the $C$ \# language as a language to compile logic and uses visual studio as an application to display $C$ \# language logic lines and acts as an IDE so that the logic lines that have been compiled can be processed into an application, and use devexpress as an additional application for visual studio which contains controls that can help to create an application.The method used in developing this system uses the Extreme Programming method, while the methods for collecting the funds use observation, interviews and literature study.By utilizing this work ability grouping application, it makes it easier for users to map the information needed about the ability of each employee to work.

\begin{abstract}
Abstrak
Dengan adanya teknologi informasi yang sangat maju seperti sekarang ini, tentu sangat membantu pekerjaan manusia dalam membuat, mengubah dan mencari informasi. Proses pencarian informasi di Telkomsigma Jakarta masih menggunakan sistem yang belum terkomputasi dengan baik. Pada perancangan aplikasi pengelompokan bakat kemampuan berkerja ini penulis menggunakan bahasa C\# sebagai sebuah bahasa untuk menyusun logika serta menggunakan visual studio sebagai sebuah aplikasi untuk menampilkan baris logika bahasa C\# dan bertindak sebagai IDE agar baris logika yang telah tersusun dapat diproses untuk menjadi sebuah aplikasi, dan menggunakan devexpress sebagai aplikasi tambahan untuk visual studio yang berisi kontrol-kontrol yang dapat membantu untuk membuat sebuah aplikasi. Metode yang digunakan dalam pengembangan sistem ini menggunakan metode Extreme Programming sedangkan metode dalam pengumpulan danya menggunakan pengamatan, wawancara dan studi pustaka. Dengan pemanfaatan aplikasi pengelompokan bakat kemampuan bekerja ini, membuat pengguna lebih mudah dalam memetakan informasi yang dibutuhkan tentang kemampuan masing-masing bekerja pegawai.
\end{abstract}

\section{PENDAHULUAN}

Telkomsigma merupakan salah satu perusahaan yang bergerak dibidang Informasi dan Teknologi (Informations \& Communications Technology - ICT) yang sudah berpengalaman selama kurang lebih 22 tahun dan merupakan pioneer diareanya yang merupakan anak perusahaan dari PT. TELEKOMUNIKASI INDONESIA, Tbk.

Berdasarkan observasi yang dilakukan oleh penulis pengelompokan bakat yang dilakukan di Telkomsigma biasanya tidak memiliki format baku sehingga masing-masing kepala unit akan membuat format pengelompokan bakatnya sendiri, dan hasil pengelompokan 
bakat akan di isi oleh masing-masing pegawai menggunakan excel lalu di kumpulkan ke kepada unit yang bertanggung jawab.

Setelah itu admin akan merekap dan memberikan penilaian secara manual berdasarkan masukan data dari masing-masing kepala unit, namun banyaknya data dapat menyebabkan human error yang nantinya dapat mengakibatkan hilangnya data, atau penilaian yang di lakukan salah menggunakan rumus.

Berdasarkan uraian di atas maka penulis dapat menyimpulkan topik sebagai laporan Skripsi dengan judul "Rancang Bangun Pengelompokan Bakat Dalam Bekerja Pada Telkomsigma Jakarta”.

\section{TINJAUAN PUSTAKA}

Menurut Pressman (2010), perancangan atau rancang bangun merupakan serangkaian prosedur untuk menterjemahkan hasil Analisa dan sebuah system ke dalam bahasa pemrograman untuk mendeskripsikan dengan detail bagaimana komponen-komponen sistem di implementasikan.

Pengertian pembangunan atau bangun sistem adalah kegiatan menciptakan sistem baru maupun mengganti atau memperbaiki sistem yang telah ada secara keseluruhan.

Jadi dari pendapat diatas dapat disimpulkan bahwa rancang bangun adalah proses penggambaran sebuah sistem dari hasil analisa ke dalam suatu bentuk bahasa pemrograman untuk kemudian di perbaiki atau melakukan peningkatan dari sistem yang sudah ada.

Menurut De Vito (1997) kelompok merupakan sekumpulan individu yang cukup kecil bagi semua anggota untuk berkomunikasi secara relatif mudah. Para anggota saling berhubungan satu sama lain dengan beberapa tujuan yang sama dan memiliki semacam organisasi atau struktur diantara mereka. Kelompok mengembangkan norma-norma, atau peraturan yang mengidentifikasi tentang apayang dianggap sebagai perilaku yang diinginkan bagi semua anggotanya.

Bakat (aptitude) mengandung makna kemampuan bawaan yang merupakan potensi (potential ability) yang masih perlu pengembangan dan latihan lebih lanjut. Karena sifatnya yang masih bersifat potensial atau masih laten, bakat merupakan potensi yang masih memerlukan ikhtiar pengembangan dan pelatihan secara serius dan sistematis agar dapat terwujud. Bakat berbeda dengan kemampuan (ability) yang mengandung makna sebagai daya untuk melakukan sesuatu, sebagai hasil pembawaan dan latihan. Bakat juga berbeda dengan kapasitas (capacity) dengan sinomimnya, yaitu kemampuan yang dapat dikembangkan di masa yang akan datang apabila latihan dilakukan secara optimal. Dengan demikian, dapat disarikan bahwa bakat masih merupakan suatu potensi yang akan muncul setelah memperoleh pengembangan dan latihan. Adapun kemampuan dan kapasitas sudah merupakan suatu tindakan yang dapat dilaksanakan atau akan dapat dilaksanakan. Jadi, yang disebut bakat adalah kemampuan alamiah untuk memperoleh pengetahuan dan keterampilan, baik yang bersifat umum maupun yang bersifat khusus.

Menurut Soelaiman adalah sifat yang dibawa lahir atau dipelajari yang memungkinkan seseorang yang dapat menyelesaikan pekerjaan, baik secara mental maupun fisik. Karyawan dalam suatu organisasi, meskipun dimotivasi dengan baik, tetapi tidak semua memiliki kemampuan untuk bekerja dengan baik. Kemampuan dan keterampilan memainkan peranan utama dalam perilaku dan kinerja individu. Keterampilan adalah kecakapan yang berhubungan dengan tugas yang dimiliki dan dipergunakan oleh seseorang para waktu yang tepat.

Menurut Herudiati, 2013 mendefinisikan makna kerja merupakan penghayatan individu dalam memenuhi kebutuhan ekonomi dengan melakukan bekerja dalam sebuah lingkungan kerja. Selain itu kerja juga dapat di artikan sebagai suatu kontribusi yang signikifikan untuk menemukan tujuan hidup seseorang. Kondisi ini mendukung untuk melaksanakan pekerjaan dengan semangat kerja dan pandangan yang menjadi dasar spiritual seorang dalam bekerja. Hal ini kesesuaian tugas dengan motivasi diri dalam bekerja yang bertujuan untuk mendapatkan penghargaan atas hasil kerja.

\section{METODE PENELITIAN}

Pada penelitian ini digunakan jenis penelitian kualitatif dengan metode studi kasus. Penelitian kualitatif adalah penelitian yang bermaksud untuk memahami fenomena tentang apa yang dialami oleh subjek penelitian misalnya perilaku, persepsi, motivasi, tindakan dan lainlain secara holistik dan dengan cara deskripsi dalam bentuk kata-kata dan bahasa, pada suatu 
konteks khusus yang alamiah dan dengan memanfaatkan berbagai metode alamiah (Moleong, 2011). Berdasarkan latar belakang masalah serta tujuan yang telah diuraikan pada bab 1 , penulis menggunakan pendekatan kualitatif yaitu berawal pada data dan berakhir pada kesimpulan. Dengan adanya batasan masalah maka penelitian yang dilakukan pada objek penelitian dimungkinkan tidak melebar dari tujuan yang ingin dicapai, sehingga pengumpulan data dapat dilakukan secara tepat. Metode yang digunakan dalam penelitian ini adalah studi kasus dimana penulis berusaha untuk mengetahui bagaimana proses pengelompokan bakat yang dilakukan oleh perusahaan. Penulis mengumpulkan dan mendiskripsikan proses sistem yang berjalan dengan keadaan sebenarnya yang terjadi di lokasi penelitian tersebut.

Tahapan penelitian mencakup langkah-langkah pelaksanaan penelitian dari awal sampai akhir. Masing-masing Langkah penelitian digambarkan dan diuraikan secara rinci sebagai berikut:

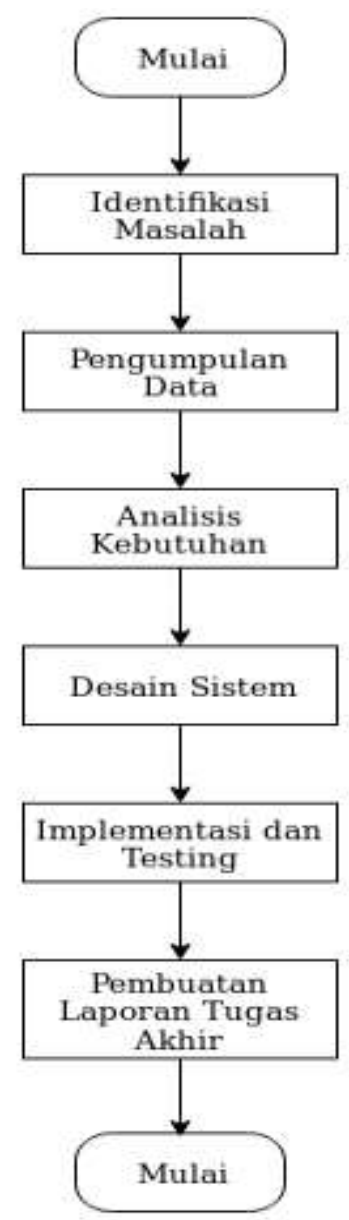

1. Identifikasi Masalah

Tahap awal dalam penelitian ini adalah identifikasi masalah yang akan dijadikan sebagai objek penelitian. Identifikasi masalah dilakukan dengan terlebih dahulu melihat kondisi aktual di lapangan. Setelah diidentifikasi barulah masalah itu dirumuskan kemudian langkah selanjutnya adalah menentukan tujuan dari penelitian. Tujuan penelitian ini merupakan sasaran yang nantinya ingin diwujudkan dari penyelesaian permasalahan yang diteliti.

2. Pemgumpulan Data

Metode yang digunakan untuk mengumpulkan data pada penelitian ini ada tiga yaitu :

\section{Observasi}

Tahapan ini merupakan tahapan pengamatan menyeluruh terhadap sistem yang sedang berjalan di Telkomsigma Jakarta, khususnya pada sistem pengelompokan bakat dalam bekerja pegawai perusahaan. Selama pengamatan penulis menemukan beberapa kekurangan - kekurangan, setelah itu diambil sebuah kesimpulan sementara mengenai masalah - masalah tersebut.

2. Wawancara

Wawancara dilakukan dengan cara mewawancarai langsung beberapa pihak terkait, yang berguna untuk mendapatkan informasi maupun data-data yang dibutuhkan untuk perancangan sistem yang akan dibangun, yaitu:

a. Penulis melakukan wawancara kepada Bapak Dani Luthfiansyah sebagai Manager Presales

b. Penulis melakukan wawancara kepada Bapak Eki Hely sebagai Staff Presales. 3. Studi Pustaka

Studi pustaka dilakukan dengan melakukan pencarian terhadap buku buku yang berhubungan dengan penelitian, karya-karya ilmiah maupun jurnal, baik yang terdapat diperpustakaan maupun yang terdapat di internet, yang dijadikan referensi dalam penyusunan skripsi ini sehingga data-data yang disajikan dapat dipertanggung jawabkan.

3. Analisa Kebutuhan

Analisa kebutuhan aplikasi dilakukan untuk mengetahui kebutuhan pengguna terhadap aplikasi yang dikembangkan. Hal ini perlu dilakukan agar aplikasi yang dikembangkan sesuai dengan kebutuhan pengguna.

4. Desain Sistem 
Pada tahap ini penulis membuat perancangan sistem yang akan di usulkan. Perancangan tersebut meliputi, merancang tampilan user, merancang basis data untuk sistem tersebut agar manajemen file yang ada lebih teratur, kemudian yang terakhir adalah merancang coding program dari suatu informasi.

5. Implementasi Sistem dan Pengujian Implementasi dan pengujian adalah proses untuk memastikan bahwa aplikasi yang dikembangkan bebas dari kesalahan. Pada tahap ini juga akan dilakukan evaluasi terhadap hasil penelitian yang dilakukan. Evaluasi dilakukan mencakup evaluasi hasil dan manfaat cara dengan membandingkan hasil yang didapatkan dengan kebutuhan pengguna.

6. Pembuatan Laporan Skripsi

Langkah terakhir dari penelitian ini adalah membuat laporan skripsi. Laporan ini berisi hal-hal yang dikerjakan selama penelitian dan hasil yang didapatkan pada saat melakukan penelitian. Dalam penulisan, format yang digunakan adalah berdasarkan format yang telah ditentukan oleh prodi teknik informatika Universitas Muhammadiyah Tangerang.

a. Diagram SIPOC

Pada tahapan analisa sistem ini penulis menggunakan diagram SIPOC (SupplierInputs-Process-Outputs-Customer), diagram ini memberikan gambaran secara umum terhadap proses yang ada saat ini. Diagram SIPOC merupakan alat yang dipakai dalam penerapan peningkatan kualitas. Proses analisa dilakukan terhadap hasil tahapan pengumpulan data dengan wawancara, observasi, dan studi pustaka untuk mendapatkan spesifikasi kebutuhan sistem yang akan di gunakan.

Pada proses analisa, teknis yang dilakukan adalah:

1. Analisa data dan informasi. Analisa dilakukan terhadap prosedur dan pengamatan terhadap sistem yang berjalan saat ini.

2. Analisa kebutuhan fungsional, NonFungsional, dan Pengguna. Pemodelan kebutuhan fungsional untuk menggambarkan fungsi sistem dan pengguna yang terlihat, serta fungsi-fungsi apa saja yang bisa didapatkan oleh masing-masing pengguna dimodelkan dengan Use Case Diagram.

3. Analisa Perilaku Sistem. Pada tahap ini, dilakukan analisa perilaku sistem yang dikembangkan dan dimodelkan dengan Unified Modeling Language (UML). b. Skala Linkert

Skala Likert adalah suatu skala psikometrik yang umum digunakan dalam angket dan merupakan skala yang paling banyak digunakan dalam riset berupa survei. Nama skala ini diambil dari nama Rensis Likert, yang menerbitkan suatu laporan yang menjelaskan penggunaannya. Sewaktu menanggapi pertanyaan dalam skala Likert, responden menentukan tingkat persetujuan mereka terhadap suatu pernyataan dengan memilih salah satu dari pilihan yang tersedia. Biasanya disediakan lima pilihan skala dengan format seperti ini:

$\begin{array}{ll}\text { 1. } & \text { Sangat tidak setuju } \\ \text { 2. } & \text { Tidak setuju } \\ \text { 3. } & \text { kurang setuju } \\ \text { 4. } & \text { Setuju } \\ \text { 5. } & \text { Sangat setuju }\end{array}$

Selain pilihan dengan lima skala seperti contoh di atas, kadang digunakan juga skala dengan tujuh atau sembilan tingkat. Suatu studi empiris menemukan bahwa beberapa karakteristik statistik hasil kuesioner dengan berbagai jumlah pilihan tersebut ternyata sangat mirip.

Skala Likert merupakan metode skala bipolar yang mengukur baik tanggapan positif ataupun negatif terhadap suatu pernyataan. Empat skala pilihan juga kadang digunakan untuk kuesioner skala Likert yang memaksa orang memilih salah satu kutub karena pilihan "netral" tak tersedia.

\section{PERANCANGAN SISTEM}

Pengembangan Rancang Bangun Pengelompokan Bakat Dalam Bekerja ini dengan menggunakan Bahasa pemrograman $\mathrm{C \#}$ yang di proses dengan menggunakan IDE Visual Studio 2017 dengan metode extreme programming dengan tahapan Planning, Design, Coding, Testing. 


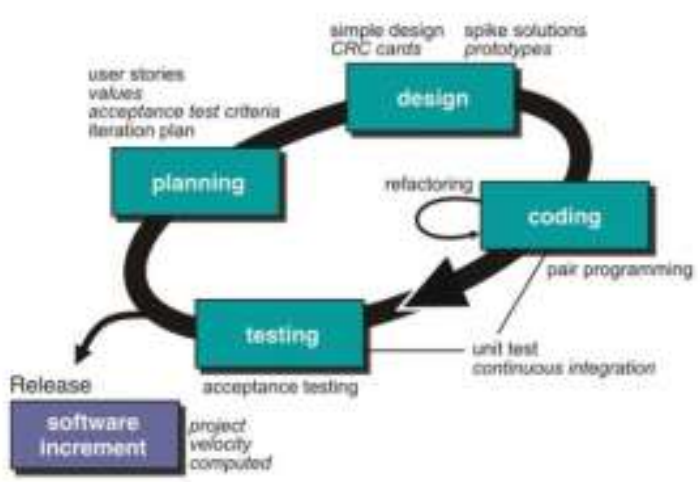

Bakat yang di maksud didalam aplikasi ini adalah penilaian terhadap kinerja dari masingmasing karyawan Telkomsigma Jakarta yang nantinya akan di petakan ke dalam 9 jenis kriteria dianataranya:

- Star

- Star adalah nilai tertinggi yang bisa di dapatkan oleh seorang karyawan di Telkomsigma, hadiah yang di berikan perusahaan biasanya adalah sertifikasi training yang memberikan keuntungan untuk kenaikan grade dan gaji sebesar $1-5 \%$ di kemudian hari.

- Strong Performer

- Strong Performer adalah nilai ke 2 tertinggi yang bisa di dapatkan oleh seorang karyawan di Telkomsigma, hadiah yang di berikan perusahaan biasanya adalah kenaikan gaji sebesar $1 \%-5 \%$ di kemudian hari.

\section{- Contributor}

- Contributor adalah nilai ke 3 tertinggi yang bisa di dapatkan oleh seorang karyawan di Telkomsigma, hadiah yang di berikan perusahaan biasanya adalah sebuah insentif.

- Rising Star

- Rising Star adalah nilai ke 4 tertinggi yang bisa di dapatkan oleh seorang karyawan di Telkomsigma.

- Solid Performer

- Solid Performer adalah nilai ke 5 tertinggi yang bisa di dapatkan oleh seorang karyawan di Telkomsigma

- Acceptable Performer

- Acceptable Performer adalah nilai ke 6 tertinggi yang bisa di dapatkan oleh seorang karyawan di Telkomsigma.

- Question Mark
- Question Mark adalah nilai ke 7 tertinggi yang bisa di dapatkan oleh seorang karyawan di Telkomsigma, namun biasanya jika mendapatkan nilai ini karyawan tersebut akan di pantau langsung oleh tim leader.

- Marginal Performer

- Marginal Performer adalah nilai ke 8 tertinggi yang bisa di dapatkan oleh seorang karyawan di Telkomsigma, namun biasanya jika mendapatkan nilai ini karyawan tersebut akan di pantau langsung oleh tim leader dan di berikan teguran keras yang apabila tidak di dilaksanakan maka akan berakibat ke pemberian surat peringatan.

- Low Performer

- Low Performer adalah nilai terendah yang bisa di dapatkan oleh seorang karyawan di Telkomsigma, namun biasanya jika mendapatkan nilai ini karyawan tersebut akan di pantau langsung oleh tim leader dan di berikan surat peringatan, apabila surat peringatan sudah 2 kali di berikan aman akan di lakukan pemotongan gaji sesuai kinerja yang di berikan, apabila pola tersebut terjadi sebanyak 2 kali atau lebih maka karyawan akan di berhentikan oleh perusahaan.

\section{HASIL DAN PEMBAHASAN}

Berikut ini adalah rancangan front end dari Rancang Bangun yang akan di buat

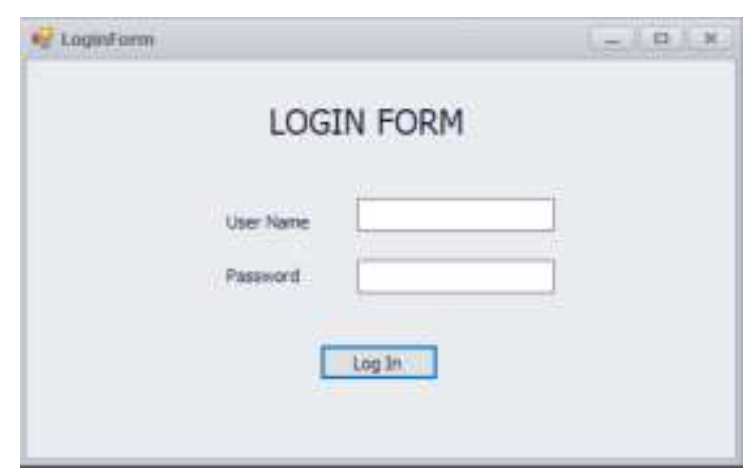

Gambar 1 Tampilan Login 


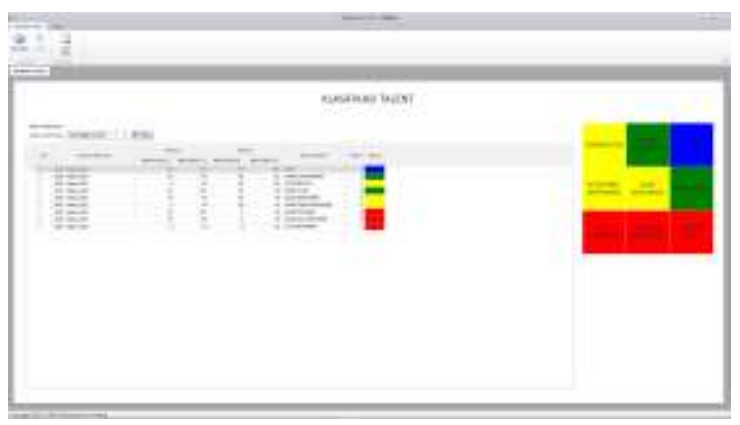

Gambar 2 Klasifikasi Bakat

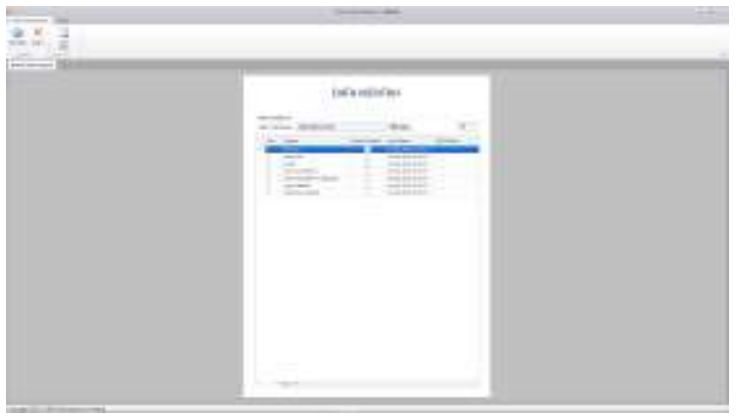

Gambar 3 Isian Format Data Mentah

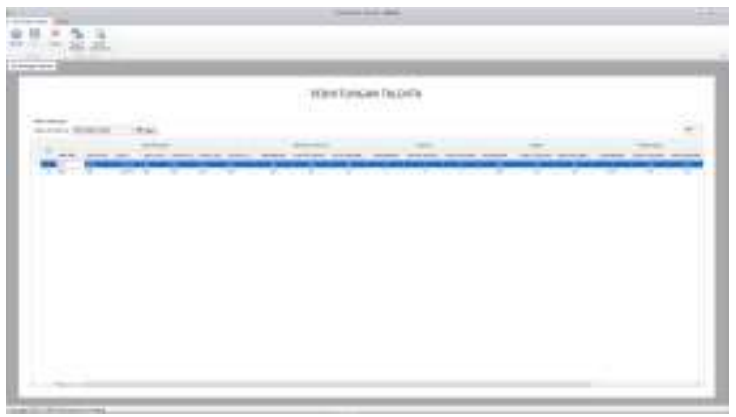

Gambar 4 Perhitungan Talenta

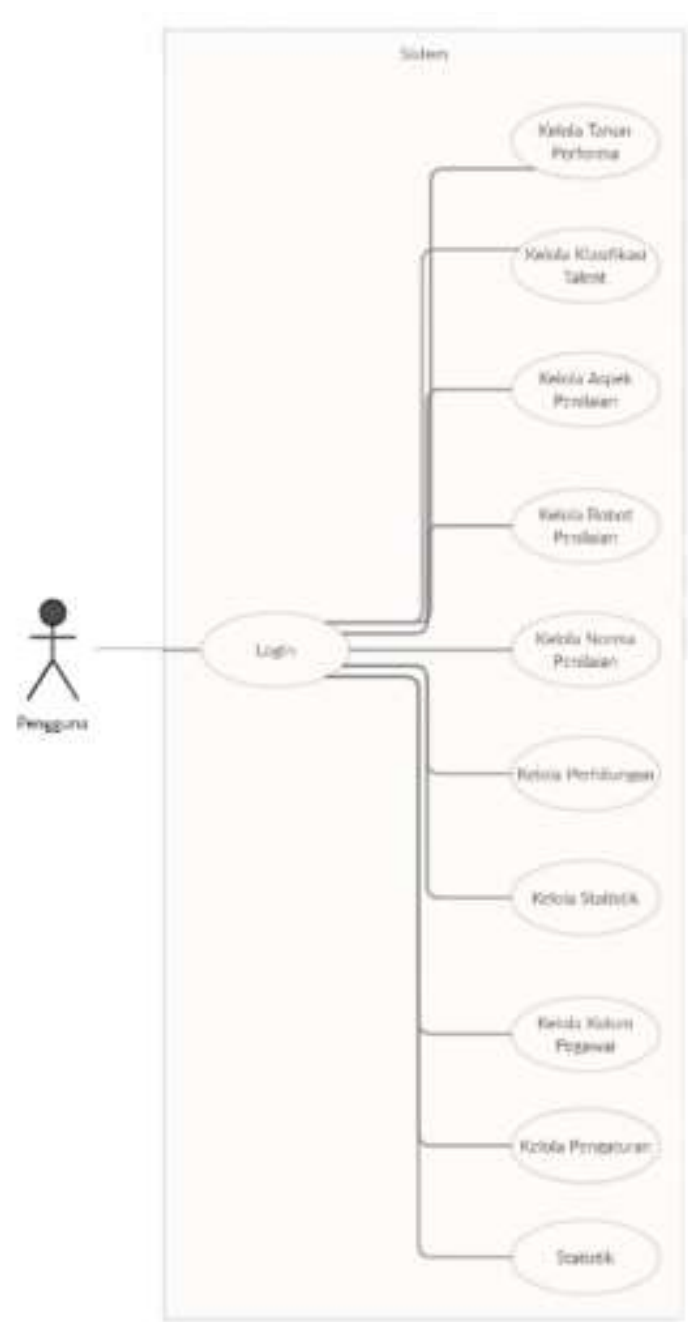

Gambar 5 Rancangan Use Case

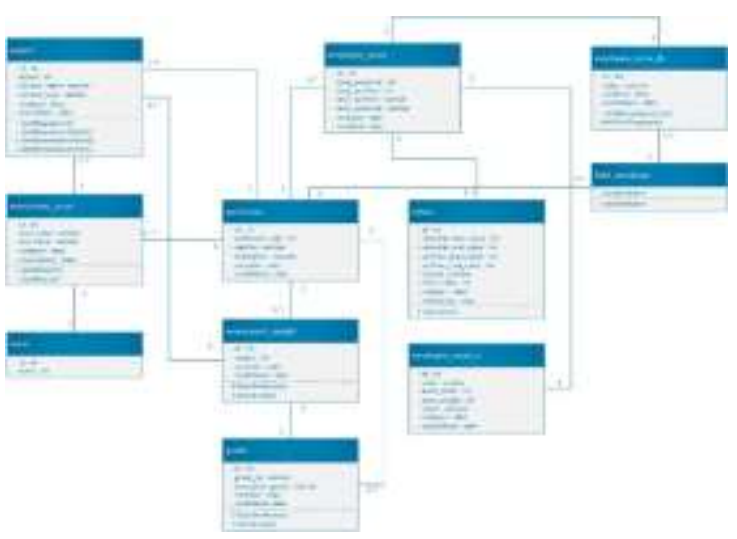

Gambar 6 Rancangan Class Diagram

\section{KESIMPULAN}

Berdasarkan hasil dan Analisis diatas maka penulis dapat mengambil kesimpulan berikut : 
- Membangun Rancang Bangun dengan menggunakan $\mathrm{C \#}$ yang memiliki kemampuan untuk mengolah masukan parameter yang berfungsi sebagai format yang akan digunakan sebagai dasar pengelompokan bakat.

- Dengan menggunakan SQLite data dapat tersimpan dengan baik dan dengan SQLite data dapat dihubungkan dengan logika $\mathrm{C \#}$ yang menjadi antarmuka dalam menyimpan data.

- Dengan menggunakan pemetaan nilai yang telah di tentukan dalam format pada aplikasi rancang bangun pengelompokan bakat dalam bekerja.

\section{REFRENSI}

Andik Asmara, Haryanto, "Pengembangan Tes Minat dan Bakat Dengan Metode Jaringan Syaraf Tiruan (JST) Untuk Memprediksi Potensi Siswa Bidang Robotika", Jurnal Pendidikan Vokasi, Vol 5, No.3, e-ISSN 2528-2476, 2015

A.S Rosa dan Salahuddin M, 2011. Modul Pembelajaran Rekayasa Perangkat Lunak (Terstruktur dan Berorientasi Objek), Modula, Bandung.

Gaspersz, Vincent. (2010). Pedoman Implementasi Program Six Sigma Terintegrasi dengan ISO 9001 : 2000, MBNQA dan HACPP,Jakarta : PT. Gramedia Pustaka UtGaspersz, Vincent. 2010. Lean Six Sigma for Manufacturingand Service Industries. Jakarta : PT. Gramedia Pustaka Utama.

Herudiati. 2013. Makna Kerja bagi Satuan Pengaman (Security) Perempuan (Studi Fenomenologi Satpam Perempuan Jawa). Tesis. Program Magister Sains Psikologi. Fakultas Psikologi. UGM.

Komariah, Aan \& Satori, Djam'an. (2012). Metodologi Penelitian Kualitatif. Bandung: Alfabeta.

Konixbam (2009). Aplikasi Dekstop menggunakan VB. Net. Surabaya
Mega Suryani, Erny Roesmaningsih, "Sistem Pengelompokan Peserta Didik Dalam Pelayanan Program Keberbakatan di SD Muhammadiyah 15 Surabaya", Jurnal Universitas Negeri Surabaya, Vol 7, No. 1, e-ISSN $2252-8253,2019$

Mohammad Ali dan Mohammad Asrori, Psikologi Remaja: Perkembangan Peserta

Didik, (Jakarta: PT bumi aksara, 2014)

Nugroho, Adi. 2010. Analisis dan Perancangan Sistem Informasi dengan Metodologi Berorientasi Objek, Informatika: Bandung.

Pressman, R.S. (2010), Software Engineering : a practitioner's approach,

McGraw-Hill, New York

Simarmata, Janner. (2010). Perancangan Basis Data. Yogyakarta: CV. Andi Ofsset.

Soelaiman, 2007, Manajemen Kinerja ; Langkah Efektif untuk Membangun,

Mengendalikan dan Evaluasi Kerja, Cetakan Kedua, Jakarta: PT. Intermedia Personalia Utama.

Widya Safira Azis, Dedy Atmajaya, "Pengelompokan Minat Baca Mahasiswa Menggunakan Metode KMeans", Jurnal Ilmiah ILKOM, Vol 8, No. 2, e-ISSN 2087-1716, 2016 